\title{
Restituir las tierras en el marco del posconflicto colombiano: una mirada al caso indígena Wiwa de la Sierra Nevada de Santa Marta
}

\author{
Alexandra D'Angelo - Universitat Autònoma de Barcelona ${ }^{1}$
}

DOI: https://doi.org/10.5565/rev/periferia.618

\begin{abstract}
Resumen
Colombia es uno de los países del mundo con mayor número de desplazados internos como consecuencia del conflicto armado que ha caracterizado su historia reciente. Entre las principales víctimas, las comunidades indígenas del país ocupan un lugar importante, ya que sus territorios aislados han sido considerados atractivos y estratégicos por parte de los actores de la violencia. Hoy en día, el Estado colombiano tiene entre sus principales objetivos el de la reparación a las víctimas y, para lograrlo, ha implementado la "Ley $\mathrm{N}^{\circ} 1448 / 11$ de Víctimas y Restitución de Tierras" que permite a las comunidades víctimas de desplazamiento forzado de reclamar sus territorios. El objetivo del presente ensayo es poner luz sobre las dinámicas de los procesos de restitución territorial, los actores involucrados y las paradojas del proceso mismo, utilizando el análisis de un caso de estudio específico: el territorio indígena Wiwa de la Sierra Nevada de Santa Marta.
\end{abstract}

Palabras clave: restitución de tierras, desplazados internos, Colombia, territorios indígenas, posconflicto

Abstract. The restitution of lands after the armed conflict in Colombia: the case of the indigenous territory of the Wiwa people in Sierra Nevada de Santa Marta.

Consequent to the armed conflict that has characterized its recent history, Colombia has one of the highest levels of internal displaced people in the world. The indigenous peoples are among the main victims as the perpetrators of violence have always considered their territories as being attractive and strategicallyplaced. Nowadays, one of the primary objectives of the Colombian government is to compensate the victims for the damage caused, and to do so, the Victims and Land Restitution Law $\mathrm{N}^{\circ} 1448 / 11$ was passed, allowing forced displacement communities to reclaim their land. The aim of this article is to shed light on how the process of land restitution is unfolding, on the actors involved and on the paradoxes of the process itself through the analysis of a specific study case: the territory of the indigenous community of the Wiwa in Sierra Nevada de Santa Marta.

\footnotetext{
${ }^{1}$ Enviar correspondencia a: Alexandra D'Angelo, alexandra.dangelo93@gmail.com
} 
Alexandra D'Angelo, Restituir las tierras en el marco del posconflicto colombiano: una mirada al caso indígena Wiwa de la Sierra Nevada de Santa Marta, perifèria 22(2), diciembre 2017 revistes.uab.cat/periferia

Keywords: restitution of lands, internal displaced, Colombia, indigenous territories, post-conflict

\section{Introdución}

El presente artículo es el fruto del trabajo final de Máster en "Antropología: investigación avanzada e intervención social" de la Universitat Autònoma de Barcelona, cursado durante el año académico 2016-2017. La investigación que ha caracterizado la tesina ha representado la segunda etapa de una investigación más amplia, centrada en el tema de la restitución territorial a las víctimas de desplazamiento forzado, en el marco del posconflicto colombiano. De hecho, Colombia ha sido declarado el país que encabeza el listado de países del mundo en número de desplazados internos, contando con 6,9 millones de desplazados a lo largo de los últimos 30 años (1985-2015), lo cual representa casi el 13\% de la población total (Amnistía Internacional, 2014). Un gran número de víctimas por desplazamiento forzado han sido familias de campesinos 0 miembros de comunidades indígenas y afrodescendientes, que se han visto obligados a abandonar sus territorios de origen y buscar refugio en las principales ciudades colombianas, a menudo en condiciones de extrema pobreza. Mientras tanto, sus tierras han quedado bajo el control de grupos armados ilegales o del ejército colombiano, siendo la mayor parte de estas tierras zonas estratégicas para bases escondidas o para campos de cultivos ilegales. En el presente, el país se enfrenta a las consecuencias de la violencia, que es considerada culpable de la mayoría de las problemáticas actuales del país, como el uso de las tierras durante el conflicto (Amnistía Internacional, 2014). Por este motivo el Estado colombiano ha optado por la creación de la "Ley de Víctimas y de Restitución de Tierras": la Ley Nº 1448 de 2011, que constituye el tema central del presente ensayo. El objetivo principal de este artículo es observar las características, el funcionamiento y los actores involucrados en el proceso de restitución. En particular, se tomará un enfoque dirigido a la restitución de tierras indígenas, en el caso de estudio de la comunidad indígena Wiwa de la Sierra Nevada de Santa Marta, al norte del país. En este escenario más específico, se revisará el significado que posee el territorio para la 
Alexandra D'Angelo, Restituir las tierras en el marco del posconflicto colombiano: una mirada al caso indígena Wiwa de la Sierra Nevada de Santa Marta, perifèria 22(2), diciembre 2017 revistes.uab.cat/periferia

comunidad Wiwa y sus implicaciones en el proceso de restitución territorial. Cabe mencionar que en la normativa creada con la Ley $1448 / 11$ y sus sucesivos decretos, se menciona y se solicita la aportación de profesionales de las ciencias sociales, los cuales deben utilizar sus herramientas para entregar conocimientos útiles al desarrollo de las restituciones. Por este motivo, se mirará también al rol de los profesionales de la antropología en este peculiar caso de intervención social, que encajaría en el marco de la antropología aplicada a las políticas públicas.

La investigación en la que se basa el presente artículo no se habría podido realizar sin un trabajo de campo previo, llevado a cabo entre octubre y diciembre de 2015 en el asentamiento de la comunidad indígena Wiwa de Gotzeshi de la Sierra Nevada de Santa Marta. Este trabajo de campo formó parte de la fase preliminar del proyecto de Restitución de Tierras llevado a cabo por la agencia de Cooperación Internacional UPD (Unidad de Planificación y Desarrollo), en colaboración con la Organización indígena Casa Indígena de Santa Marta y la Universidad del Magdalena (Santa Marta). Contratada por UPD, mi participación se centró en un doble objetivo: una caracterización del territorio que la comunidad indígena Wiwa había solicitado para su restitución, y una caracterización de las afectaciones, o sea de las violaciones y violencias sufridas por las víctimas.

La segunda fase de la investigación ha constituido el trabajo de tesis final del Máster en "Antropología: investigación avanzada e intervención social" de la Universitat Autònoma de Barcelona, bajo la tutoría de la Doctora Montserrat Ventura i Oller. Esta segunda fase ha tratado de alguna manera de alejarse de la visión exclusiva indígena con el fin de abrir el estudio a un punto de vista más amplio del contexto, poniendo énfasis en las instituciones encargadas de la restitución, los actores involucrados y las dificultades que se encuentran en el camino hasta la devolución. Para alcanzar los objetivos específicos de la segunda etapa investigativa, se han utilizado datos recolectados a través, por un lado, de la investigación bibliográfica y, por otro lado, datos de dominio público producidos por varios órganos del gobierno (informes gubernamentales, estadísticas de las entidades de restitución de tierras, informes de las organizaciones para los 
Alexandra D'Angelo, Restituir las tierras en el marco del posconflicto colombiano: una mirada al caso indígena Wiwa de la Sierra Nevada de Santa Marta, perifèria 22(2), diciembre 2017 revistes.uab.cat/periferia

derechos humanos, entre otros). Junto a esto, se ha contactado con siete informantes con los que se llevaron a cabo entrevistas semiestructuradas ${ }^{2}$. Entre ellos, sobre todo se ha contactado con expertos del conflicto y del posconflicto colombiano, profesionales involucrados en el trabajo de la restitución territorial (en particular abogados o antropólogos de la Unidad de Restitución de Tierras) y antropólogos y antropólogas expertos en la región de Sierra Nevada de Santa Marta.

El presente articulo se divide en tres bloques: en un primer momento se apuntarán algunas nociones teóricas que puedan apoyar el análisis del contexto estudiado desde la antropología. En el segundo bloque se describirá la situación históricopolítica colombiana que ha llevado al momento histórico actual y, finalmente, se analizará el proceso de restitución de tierras y el caso de estudio del territorio Wiwa de la Sierra Nevada de Santa Marta.

\section{Antropología, orientación social y desarrollo}

Desde sus comienzos, y en las diversas áreas geográficas en las cuales se ha desarrollado la disciplina antropológica, la aplicación y el uso del conocimiento para intervenciones sociales se ha entendido de diferentes maneras $y$, entre ellas, algunas se han excluido mutuamente (Duque-Páramo, 2010). En otras palabras, si en algunos casos no se observa una correspondencia entre nuestra disciplina y su aplicabilidad, en otros la antropología es percibida directamente como algo involucrado en asuntos de política pública o de proyectos de desarrollo: los antropólogos y las antropólogas, en estos casos, son llamados a tomar parte en proyectos que tienen como objetivo un cambio social, integrando la mirada antropológica a la intervención social en una multitud de ámbitos sociales. En los

\footnotetext{
2 Se citará a los entrevistados en la siguiente manera: E1, E2, E3 etc. seguidos por la fecha de la entrevista.
} 
Alexandra D'Angelo, Restituir las tierras en el marco del posconflicto colombiano: una mirada al caso indígena Wiwa de la Sierra Nevada de Santa Marta, perifèria 22(2), diciembre 2017

\section{revistes.uab.cat/periferia}

debates contemporáneos, algunos antropólogos han puesto énfasis en la correspondencia entre teoría antropológica y práctica social: Aurelio Díaz (1998) y Teresa San Román (2006) concuerdan en la idea de que es "erróneo contraponer la investigación básica y la aplicada, como si formaran parte de dos ámbitos inconexos" (Díaz, 1998:25). Ambos autores critican la ideología común que considera la investigación aplicada como carente de cientificidad, "superficial o menos rigurosa de la académica" (San Román, 2006:387). Hay intelectuales, sin embargo, que deconstruyen esta jerarquía y que ponen énfasis en la vinculación estrecha entre antropología básica y aplicada. Entre ellos, la misma San Román (2006) enfatiza que los profesionales de la antropología tienen mucho que decir sobre diversos ámbitos de acción, dándole también importancia a la utilización de herramientas propias de diferentes disciplinas.

En los años posteriores a la segunda guerra mundial, un ámbito clave en el cual la antropología ha tenido un papel importante por su colaboración con administraciones y entidades públicas ha sido el de la cooperación internacional y los proyectos de desarrollo. La cooperación internacional nació en el contexto histórico-político de los años cincuenta, y su origen fue guiado por la voluntad de Estados Unidos de entregar ayudas a una Europa inestable a través del Plan Marshall del gobierno Truman, en 1948. Con el pasar de los años, estos proyectos se ampliaron hasta los países recién descolonizados, que en este período se empezaban a llamar tercer mundo. Ha sido a partir de los años sesenta que la antropología tuvo un papel cada vez más importante dentro de este proceso, y a partir de los setenta se dio "una transformación significativa en el concepto de desarrollo, trayendo a primer plano los factores sociales y culturales de los proyectos" (Escobar, 1999:4). Por este motivo, paulatinamente se llegó a institucionalizar el papel de los antropólogos (Escobar, 1999).

Dentro del intenso debate interno de la disciplina antropológica acerca del desarrollo, una de las corrientes más radicadas en las producciones recientes es el enfoque del 'posdesarrollo'. Esta corriente fue creada por una gama de autores "cuyo denominador es su postura radicalmente contraria a todo lo que es 
Alexandra D'Angelo, Restituir las tierras en el marco del posconflicto colombiano: una mirada al caso indígena Wiwa de la Sierra Nevada de Santa Marta, perifèria 22(2), diciembre 2017 revistes.uab.cat/periferia

considerado desarrollo" (Valcárcel, 2006:27). Aquí, el desarrollo es concebido como un discurso de control social de los pueblos no-occidentales y como una forma de poder a través del cual occidente ha perpetuado su dominio en el mundo (Valcárcel, 2006). En cuanto al supuesto compromiso de la antropología con las instituciones que lo fomentan, se fueron distinguiendo dos corrientes: aquella que apoya la idea de un compromiso activo en los proyectos desarrollistas, y aquella que prescribe el distanciamiento y la crítica radical del desarrollo institucionalizado (Escobar, 1999). Es por esta distinción que en el día de hoy podemos hablar de 'Antropología para el desarrollo' y 'Antropología del desarrollo' (Escobar, 1999). Por un lado, los antropólogos para el desarrollo afirman que, a pesar de las contradicciones desarrollistas, se necesita desesperadamente la aportación de la antropología (Escobar, 1999:12). Por otro lado, la antropología del desarrollo asume que quienes se involucran activamente en instituciones desarrollistas no pueden ser absueltos de la violencia que el mismo concepto de desarrollo lleva consigo (Escobar, 1999).

Exactamente, como ha pasado con la antropología del desarrollo y para el desarrollo, también en el campo de las políticas públicas se ha empezado a distinguir entre aquellos profesionales de la antropología especializados en el análisis y en el estudio de cómo los procesos políticos se crean y se desarrollan, y aquellos involucrados activamente en la creación, en la modificación o en la puesta en práctica de tal o tal otra política pública. En el primer caso, la antropología de las políticas públicas aborda el tema tomando como objeto de estudio la política pública en sí misma, como algo que tiene que ser cuestionado e investigado. En el segundo caso, la antropología actúa como profesional entregando el conocimiento necesario para que una política pública sea creada. Este tipo de investigación aplicada tiene el objetivo de asesorar, crear el conocimiento adecuado sobre aspectos importantes en el momento de actuar en un determinado contexto, mediante un trabajo de tipo etnográfico. Este modelo ha sido llamado Antropología Orientada, lo cual se diferencia de una antropología de tipo Participativa en la cual el investigador tiene inexcusablemente una presencia activa que "llega a todos los ámbitos y a todas las instancias implicadas en la intervención" (San Román, 2006:404). Lo que 
Alexandra D'Angelo, Restituir las tierras en el marco del posconflicto colombiano: una mirada al caso indígena Wiwa de la Sierra Nevada de Santa Marta, perifèria 22(2), diciembre 2017

\section{revistes.uab.cat/periferia}

diferencia, por lo tanto, a los dos modelos de investigación aplicada es el grado de implicación del investigador o la investigadora.

\section{Una cuestión territorial}

Con el fin de abarcar el tema de los procesos de restitución territorial a favor de las comunidades indígenas colombianas víctimas de desplazamiento forzado, se recorrerán algunos de los estudios más influyentes sobre la relación entre comunidades indígenas latinoamericanas y sus territorios. Desde sus inicios, la antropología social y cultural se ha planteado varias preguntas acerca de la relación entre naturaleza y cultura, que encuentra expresión en la relación entre los seres humanos y el entorno en el que viven. De estas preguntas se han desarrollado varias corrientes en la antropología que han atravesado la disciplina durante todo el siglo pasado. Es así como en años recientes se ha empezado a definir una distinción entre las diferentes maneras en las que los seres humanos se relacionan con el entorno y la naturaleza. Philippe Descola es, a día de hoy, considerado como el pionero de la innovación epistemológica que tanto está caracterizando los estudios antropológicos. Dentro de la esfera de las diferentes relaciones posibles entre los seres humanos y su entorno, Descola (2004) define la manera propia de las 'sociedades occidentales' de relacionarse con el entorno como un "dualismo más o menos estanco que [...] rige la distribución de los seres, humanos y no humanos, en dos campos radicalmente distintos" (p.26). En este modo la naturaleza sería algo que queda afuera de la cultura y de la sociedad, algo que distinguimos muy claramente de nosotros. Distinguir la naturaleza como algo opuesto a la creación humana representaría "el principio rector de nuestra propia cosmología [...] que impregna tanto nuestro sentido común como nuestra práctica científica" (Descola, 2004:32). Sin embargo, el naturalismo sería solamente una de las formas posibles con la cual las sociedades del mundo dan significado a su entorno y se posicionan en ello. En la región Amazónica, por ejemplo, Descola identifica un mundo de relaciones entre seres humanos, plantas y animales que han sido definidas como 'sociales', o sea como un continuum de las relaciones entre las personas mismas (Descola, 2004). Lo que, entonces, bajo la conceptualización del 
Alexandra D'Angelo, Restituir las tierras en el marco del posconflicto colombiano: una mirada al caso indígena Wiwa de la Sierra Nevada de Santa Marta, perifèria 22(2), diciembre 2017

\section{revistes.uab.cat/periferia}

naturalismo se llamaría naturaleza, aquí sería puro objeto de la relación social, en donde la mayoría de plantas y de animales están incluidos en una comunidad de personas, con las cuales comparten códigos morales, comportamientos y facultades que ordinariamente suelen ser atribuidos solamente a los seres humanos (Descola, 2004). En este contexto, el aspecto puramente físico sería el único elemento que haría diferir los elementos del mundo animal y vegetal con los seres humanos. Es así que naturalismo, animismo, totemismo y analogismo constituyen lo que Descola (2004) define los "modos de identificación" (p.32), maneras planteadas por los seres humanos de dar significado a nuestro entorno.

Con el 'modo de identificación' de los pueblos indígenas, el territorio - concebido como espacio de socialización - se vuelve de importancia crucial para el mantenimiento de las relaciones que ocurren entre los miembros de la sociedad y como verdadera dimensión existencial de la sociedad entera (García Hierro y Surrallés, 2004). Conscientes de los valores que un territorio indígena posee, minando el territorio se mina a la existencia del pueblo indígena. Esto quiere decir que, sin el territorio, la comunidad "se vacía de sentido con efectos destructivos sobre la identidad, las creencias y la razón de ser" (García Hierro y Surrallés, 2004:292). Dada la importancia de los territorios indígenas para quien los vive, parece entonces comprensible que la territorialidad se vuelva uno de los ejes conceptuales clave en las reivindicaciones indígenas (García Hierro y Surrallés, 2004). Reflexionando además sobre el derecho, nos encontramos frente a concepciones y visiones diferentes: "el concepto de la propiedad privada es la base de todo el sistema económico occidental [...] sino también el motor de las sociedades capitalistas" (García Hierro, 2004:280). Sin embargo "muy pocos pueblos indígenas podrían atreverse a utilizar ese concepto con referencia a la tierra" (García Hierro, 2004). El aspecto jurídico de la propiedad territorial y de la titulación de las tierras a los pueblos indígenas, hoy en día, posee un papel importante en las políticas de los países latinoamericanos $y$, también, en los instrumentos internacionales de los derechos humanos. Cabe mencionar que, en las últimas décadas, el carácter diferencial del manejo de territorios indígenas ha 
Alexandra D'Angelo, Restituir las tierras en el marco del posconflicto colombiano: una mirada al caso indígena Wiwa de la Sierra Nevada de Santa Marta, perifèria 22(2), diciembre 2017

revistes.uab.cat/periferia

encontrado espacio en dos instrumentos que hoy están vigentes y son considerados como los más importantes en materia de derechos indígenas: el Convenio 169 de la OIT del año 1989 y la Declaración Universal de Derechos de los Pueblos Indígenas de la Organización de las Naciones Unidas (ONU) que fue redactada el 13 de septiembre de 2007. No obstante el compromiso que muchos países del mundo han demostrado firmando estas importantes declaraciones, los territorios indígenas, a día de hoy, siguen teniendo un alto grado de vulnerabilidad, y las entidades concernidas siguen luchando por la defensa de sus derechos fundamentales.

\section{Justicia transicional y Ley de Restitución de Tierras}

Las raíces históricas del fenómeno objeto de estudio de esta investigación surgen del largo y violento conflicto armado que ha sido protagonista de la historia reciente de Colombia, definido como el más sangriento de la historia contemporánea de los países de América Latina $\left(\mathrm{CNMH}^{3}, 2013\right)$. Secuestros, asesinatos colectivos, despojo de bienes, atentados terroristas, violencia sexual, masacres, desapariciones y desplazamientos forzados son algunos de los actos violentos que han recaído sobre la población colombiana $(\mathrm{CNMH}, 2013)$. Un gran número de las víctimas que tuvieron que llevar a cabo un desplazamiento forzado fueron campesinos o miembros de las comunidades indígenas y comunidades afrodescendientes. Esto sucedió a causa de sus extensos territorios ricos en recursos naturales o propicios para el cultivo de coca y también por su ubicación en zonas remotas del país o en áreas cercanas a las fronteras.

Actualmente, Colombia se encuentra en pleno proceso de Justicia Transicional: procesos que, en el escenario global, han sido implementados en aquellos países en donde se asistía al tránsito de regímenes autoritarios a regímenes democráticos, o de situaciones de conflicto a situaciones posconflictuales (Delgado, 2012). En

\footnotetext{
${ }^{3}$ Centro Nacional de Memoria Histórica, 2013
} 
Alexandra D'Angelo, Restituir las tierras en el marco del posconflicto colombiano: una mirada al caso indígena Wiwa de la Sierra Nevada de Santa Marta, perifèria 22(2), diciembre 2017

\section{revistes.uab.cat/periferia}

Colombia, los mecanismos de justicia transicional comenzaron a ser adoptados a raíz de las negociaciones entre el expresidente Álvaro Uribe Vélez y las Autodefensas Unidas de Colombia (AUC), durante el primer mandato de Uribe (2002-2006) (Delgado, 2014), que encontró forma en la Ley de Justicia y Paz de 2005. Posteriormente, el actual presidente Juan Manuel Santos (2010-2014; 20142018) ha apostado, en el 2012, por un acuerdo de paz con las Fuerzas Armadas Revolucionarias de Colombia (FARC), con el objetivo de desmovilizar y reinsertar en la vida civil a los combatientes de este grupo guerrillero, entre otros aspectos no menores como acciones de desarrollo rural, reparación a las víctimas y solución a la cuestión de las drogas ilícitas (Delgado, 2014:60). Bajo algunos aspectos, ambos procesos de paz han sido considerados como procesos de "justicia transicional sin transición". Respecto a la Ley de Paz de 2005, a día de hoy existe un proceso de paz formal y jurídico (como el de Juan Manuel Santos y las FARC, precisamente); sin embargo, se considera que aún faltan las condiciones básicas para su implementación, por ejemplo, el seguimiento de actos violentos y de la presencia de diferentes grupos armados que en algunas zonas del pais están llenando el vacío dejado por las FARC (E8, politóloga, 24/03/2017).

\section{El funcionamiento de la Ley de Víctimas y de Restitución de Tierras}

Con el fin de lograr el objetivo de la restitución de tierras, en el año 2011 se aprobó una ley específica dirigida a las víctimas del conflicto armado y en particular a las víctimas de desplazamiento forzado: la "Ley de Víctimas y Restitución de Tierras" (Ley No 1448 de 2011). Las entidades estatales encargadas de aplicar la Ley son la Unidad Administrativa Especial para la Atención y Reparación Integral de las Victimas (UDV) ${ }^{4}$ y la Unidad Administrativa Especial de Gestión de Restitución de Tierras Despojadas (URT) ${ }^{5}$, adscritas al Ministerio de Agricultura y Desarrollo Rural. La URT es la entidad encargada de recibir las solicitudes de los individuos o de las

\footnotetext{
${ }^{4}$ En adelante, UDV.

${ }^{5}$ En adelante, URT.
} 
Alexandra D'Angelo, Restituir las tierras en el marco del posconflicto colombiano: una mirada al caso indígena Wiwa de la Sierra Nevada de Santa Marta, perifèria 22(2), diciembre 2017 revistes.uab.cat/periferia

familias víctimas de desplazamiento, que necesitan demandar una restitución territorial. La UDV, por otro lado, es la encargada de diagnosticar los daños que un pueblo o una comunidad ha sufrido y diseñar unas reparaciones, tanto individuales como colectivas.

Cabe mencionar que la Ley 1448, promulgada el 10 de junio de 2011, delegó al presidente de la República la facultad de expedir la regulación diferencial respecto a la restitución étnica, que fue respetada con la creación de los Decretos 4633/11, 4634/11 y 4635/11, que tienen fecha de entrada en vigor el 6 de diciembre de 2011 y una vigencia de 10 años, hasta diciembre de 2021. Esta necesidad nace del hecho de que la ley de partida no tenía en su reglamentación el derecho de llevar procesos dirigidos a las comunidades indígenas del país, en cuanto no poseía el carácter de consulta previa. Se trata de la obligación por parte del Estado de consultar con antelación a una comunidad perteneciente a una minoría étnica del país, en el caso de que se quisiera poner en práctica cualquier política o cualquier proyecto estatal concerniente a su territorio o a la comunidad misma. De hecho, Colombia se ha adherido a las disposiciones dictadas por el Convenio 169 de la OIT, una de las cuales, la consulta previa, tiene un papel central. Las solicitudes que responden a las disposiciones de los tres decretos diferenciales -o sea, población indígena, población afrodescendiente y población gitana- son llevadas por un equipo especializado Ilamado Dirección de Asuntos Étnicos ${ }^{6}$.

Existen dos fases que caracterizan el proceso de la demanda de restitución después de la solicitud por parte de las víctimas: la etapa administrativa y la etapa judicial. La primera recae sobre la URT, encargada de recibir y aceptar las solicitudes, realizar el trabajo de campo y presentar las demandas ante un juez especializado. Luego, en la fase judicial, los jueces y magistrados analizan atentamente la demanda que se convertirá en una sentencia resolutiva, sea esta positiva o negativa. El Entrevistado 1, abogado de la URT en la dirección central de Bogotá,

\footnotetext{
${ }^{6}$ En adelante, DAE.
} 
Alexandra D'Angelo, Restituir las tierras en el marco del posconflicto colombiano: una mirada al caso indígena Wiwa de la Sierra Nevada de Santa Marta, perifèria 22(2), diciembre 2017

revistes.uab.cat/periferia

explicó que la etapa administrativa está compuesta por las siguientes fases: "1. Focalización, 2. Estudio preliminar y 3. Afectaciones" (E1, URT, 06/05/2017). La focalización significa determinar, junto a la comunidad, el territorio en cuestión; el estudio preliminar consta de un análisis de dos tipos: en un primer momento, un análisis del terreno -que se compone del levantamiento topográfico y de la delimitación del territorio- acompañado por la descripción de las características agrofísicas del territorio. Posteriormente, la segunda etapa del estudio preliminar pretende definir "qué tan ancestrales son los territorios, es decir qué tanta posesión de tiempos han tenido las comunidades indígenas en estas áreas" (E1, URT, 06/05/2017). Para lograrlo, la DAE posee un equipo de topógrafos como encargados de la primera etapa y un equipo de antropólogos, sociólogos e historiadores que se ocupa de la segunda. Este último equipo, además, también se ocupa de la tercera fase de la etapa administrativa: la caracterización de las afectaciones, en donde se recolectan los datos que demuestran que este territorio, y la respectiva comunidad que vivía en él, ha sido víctima del conflicto armado. Un dato importante es que, en el caso de las comunidades indígenas, la caracterización de las afectaciones incluye las violaciones que han afectado a las comunidades indígenas y también al territorio, en cuanto el Decreto diferencial 4633/11 "dirigido a las comunidades indígenas considera al territorio, por él solo, víctima del conflicto armado. Se trata de afectaciones al territorio considerado como sujeto vivo" (E1, URT, 06/05/2017). En fin, a conclusión de la etapa administrativa, se produce la inscripción -o no inscripción- del territorio en el Registro Único de Tierras Despojadas y Abandonadas Forzosamente.

\section{La restitución de tierras: ¿un logro o un fracaso?}

El número de solicitudes recibidas hasta ahora es de 103.892 demandas, las cuales han sido solicitadas por 70.756 titulares y por un total de 91.559 predios (URT, 2017). En líneas generales, tanto los funcionarios de la URT como los expertos del tema que han sido entrevistados (ej: E1, E2, E3, E4, 2017) coinciden en el hecho de considerar que las cifras efectivas han sido inferiores a lo que se esperaba. Por ejemplo, el Entrevistado 1 admite que "se esperaban por lo menos cifras que 
Alexandra D'Angelo, Restituir las tierras en el marco del posconflicto colombiano: una mirada al caso indígena Wiwa de la Sierra Nevada de Santa Marta, perifèria 22(2), diciembre 2017

revistes.uab.cat/periferia

representasen un número de 4 millones a 5 millones de personas solicitando restituciones, $y$ ese número no se va a alcanzar claramente" (E1, URT, 06/05/2017). La desilusión acerca de las cifras de restitución de tierras incluye también los casos de restitución étnica: "efectivamente es muy difícil encontrar un grupo étnico que no haya sufrido las consecuencias del conflicto armado, por la ubicación en la cual ellos están" (E1, URT, 06/05/2017). Según los datos oficiales, la URT ha realizado el proceso administrativo de caracterización de las afectaciones territoriales de un total de 25 territorios indígenas. De ellos, 24 se inscribieron en el Registro de Tierras Despojadas y Abandonadas Forzosamente (RTDAF) y solo uno quedó afuera de él (URT, 8 de febrero 2017). Actualmente, el número de solicitudes que han llegado ante los Juzgados Especializados ha sido de 20, de las cuales 5 han tenido sentencia definitiva de restitución (URT, 8 de febrero 2017).

En el momento de intentar entender las motivaciones que puedan explicar la escasez de demandas o la lentitud de los procesos de restitución, los elementos sacados a la luz han sido de diferente naturaleza y, sin duda, reflejan una situación complicada que abarca temas diversos y con una multitud de actores en juego.

a) Los tiempos

El problema temporal con respecto al avance de los procesos que caracterizan la etapa administrativa es un asunto central en los obstáculos y en la lentitud del proceso. La primera razón tiene que ver con el Decreto 4633/11, el cual obliga a que se disponga de dos meses para concluir la caracterización de las afectaciones:

"la Unidad Administrativa Especial de Gestión de Tierras Despojadas [...] identificará las afectaciones territoriales. Esta identificación se desarrollará en un plazo no mayor a 60 días" (Art. 153, Decreto 4633/11).

Sin embargo, "la caracterización de afectaciones es prácticamente una tesis de maestría, es algo gigante que requiere un personal importante" (E1, URT, 06/05/2017). La magnitud de los análisis que se requieren en esta etapa hace que 
Alexandra D'Angelo, Restituir las tierras en el marco del posconflicto colombiano: una mirada al caso indígena Wiwa de la Sierra Nevada de Santa Marta, perifèria 22(2), diciembre 2017

revistes.uab.cat/periferia

no sea fácil llevar a cabo la caracterización de manera completa: a veces se trata de territorios muy grandes, por lo cual el levantamiento topográfico requiere mucho tiempo. Para apreciar esta dificultad, sólo hay que ver algunos de los objetivos que se pretenden cumplir en esta etapa en un lapso de dos meses: la determinación del área del territorio afectado; la identificación de la formalización de la propiedad colectiva; el uso del territorio; la identificación de la función social y ecológica del mismo; la definición de los antecedentes, las circunstancias de cada daño territorial; una relación de los proyectos de extracción de recursos naturales; el censo de las comunidades y personas afectadas y una relación de los cultivos, plantaciones, bienes e infraestructuras afectadas por los hechos (Art. 154, Decreto 4633/11).

b) Persistencia del conflicto armado

En muchas zonas del país, y en muchos territorios indígenas, persiste el problema de la violencia y de la presencia de actores armados que controlan amplias áreas de aquéllos. Estos representan los casos en donde una comunidad indígena no puede demandar la restitución de tierras, puesto que los pondría en una situación de alto peligro. Efectivamente, se han verificado, a lo largo de estos años, hechos como intimidaciones, amenazas y hasta asesinatos de campesinos o líderes indígenas reclamantes de territorios despojados. Las estadísticas muestran que a partir del 2008 y hasta el 31 de enero de 2017, han sido asesinados 73 reclamantes de tierras en todo el país (Verdadabierta, 31 de enero 2017). En muchas zonas, "las condiciones siguen siendo muy difíciles, entonces hay sitios donde las opciones de retorno no son viables" (E2, antropóloga, 23/03/2017). Así pues, la gente tiene miedo de reclamar una restitución, o si se arriesga y realiza la reclamación, también puede pasar que "el Estado no se quiera meter con los grupos que allí están" (E2, antropóloga, 23/03/2017).

c) Segundos y terceros ocupantes

En su análisis de los obstáculos a la restitución de tierras, el Entrevistado 2 ha puesto énfasis sobre el desconocimiento que a menudo las leyes $-y$ en este caso el 
Alexandra D'Angelo, Restituir las tierras en el marco del posconflicto colombiano: una mirada al caso indígena Wiwa de la Sierra Nevada de Santa Marta, perifèria 22(2), diciembre 2017 revistes.uab.cat/periferia

proceso de Justicia Transicional en general - tienen del contexto en que, se supone, deben actuar. Una de estas complejidades concierne a los segundos o terceros ocupantes de las tierras o de las fincas que, o bien han sido tomadas forzosamente por los grupos armados, o bien han sido abandonadas voluntariamente por los habitantes, debido al miedo de los actos violentos que se efectuaban en los alrededores. Lo que a menudo ha sucedido, es que estos territorios abandonados han sido vendidos a otros campesinos por los dueños que huyeron de allí, los cuales, a su vez, después de un tiempo, han vendido nuevamente el terreno a un tercer campesino. El hecho de ser muy frecuente la compra y la venta no reglamentada, sobre todo en las zonas rurales y sobre todo en los años del conflicto, ha provocado que los propietarios actuales no tengan titulación en papel. Así pues, lo que se verifica hoy en día, es el hecho de que los viejos propietarios que con mucha probabilidad hoy en día están lejos del territorio en cuestión- se ven presionados para que soliciten la restitución. De este modo, los campesinos compradores, que pueden haberlo hecho de total buena fe, ahora se ven obligados a dejar sus bienes.

d) Intereses económicos

Uno de los acontecimientos que ha tenido mayores consecuencias sobre la devolución de los territorios despojados ha sido el fenómeno del ingreso de empresas, nacionales e internacionales en varias áreas del país, con la explotación minera como objetivo. Amnistía Internacional ha denunciado, de hecho, que durante las pasadas décadas, el Estado y las autoridades colombianas han otorgado licencias a empresas mineras $y$, en el caso de territorios indígenas o afrodescendientes, lo han hecho a menudo sin consulta previa (Amnistía Internacional, 2012). En una entrevista a un investigador de Amnistía Internacional se lee: "porque vivían en zonas de grandes proyectos de infraestructura, minería, de agroindustria o de hidrocarburos (Verdadabierta, 26 de noviembre 2014).

Así, el interés del Estado colombiano hacia un desarrollo económico basado en la explotación del suelo y de los recursos del país, es un asunto estrechamente 
Alexandra D'Angelo, Restituir las tierras en el marco del posconflicto colombiano: una mirada al caso indígena Wiwa de la Sierra Nevada de Santa Marta, perifèria 22(2), diciembre 2017

revistes.uab.cat/periferia

relacionado con la restitución de tierras en el marco de la Ley 1448/11. Muchos de los entrevistados han afirmado que cuando el Estado tiene un interés sobre un territorio reclamado por su restitución, se dificulta el avance del proceso (ej. E4, E2, E1, 2017). Aunque ya en el momento de la promulgación de la ley Amnistía Internacional había sacado a la luz este problema, la situación durante los últimos años ha ido agravándose aún más. El 29 de mayo de 2015, la Dirección General de la URT anunció una nueva directriz, según la cual el trabajo de la DAE debía ser supervisado por un nuevo equipo de profesionales llamado A.M.E.I (Asuntos Ambientales Minero-Energéticos e Infraestructura), siempre que los casos de análisis territorial tuvieran relación con temas de intereses estatales con respecto a los recursos naturales del país. En otras palabras, el grupo A.M.E.I está obligado a incorporarse en el proceso cuando haya una confluencia de intereses: por un lado, el interés de una comunidad étnica y por otro, el interés estatal sobre los recursos que el territorio ofrece. Esta decisión ha recibido varias críticas, y ha sido interpretada como una manera de contener las demandas por parte de las comunidades étnicas (Verdadabierta, 24 de agosto 2015). La entrevistada E4, de la Dirección de Asuntos Étnicos de la URT de Santa Marta, declaró a tal propósito:

"Cuando se dieron cuenta de que la restitución étnica pudiera llegar a traer muchos inconvenientes, entonces allí fue cuando crearon el grupo A.M.E.I, que son los que dicen «esta restitución no puede ser porque hay ese proyecto de minería que es importante para el país». Es una directriz que da el gobierno para que la restitución étnica no interfiera con la locomotora minera, que es uno de los pilares del gobierno de Santos" (E4, antropóloga URT, 13/05/2017).

\section{El proceso de restitución en la Sierra Nevada de Santa Marta}

La Sierra Nevada de Santa Marta se erige como un gran sistema montañoso entre el mar y la montaña, ubicada en la región del Caribe colombiano, en la vertiente nordeste del país. Con su forma triangular, comprende parte de los departamentos 
Alexandra D'Angelo, Restituir las tierras en el marco del posconflicto colombiano: una mirada al caso indígena Wiwa de la Sierra Nevada de Santa Marta, perifèria 22(2), diciembre 2017

\section{revistes.uab.cat/periferia}

de Magdalena, la Guajira y el Cesar (Defensoría del Pueblo, 2003). Se trata de una zona estratégica e importante por lo que concierne a los recursos naturales e hídricos del país y es considerada una zona tradicionalmente indígena, con la presencia actual de cuatro grupos: Arhuaco (44\%), Kogi (30\%), Wiwa (5\%) y Kankuamo (21\%) (Viloria de la Hoz, 2005).

En la segunda mitad del siglo pasado, la región de la Sierra Nevada de Santa Marta no ha estado exenta de los acontecimientos ligados al conflicto armado. La sombra de la violencia y del terror comenzó a difundirse en la región en aquellos años. La falta de presencia del Estado en la región creó las condiciones óptimas para que los grupos armados tomaran fuerza y control del territorio, amenazando, despojando, y asesinando a la población local. En el año 2001, Sierra Nevada de Santa Marta fue uno de los sitios del país donde más se sufrió la expulsión de la población, contando con un número de desplazados de 19.479 únicamente en ese año (Defensoría del Pueblo, 2001). Como consecuencia, los territorios indígenas de la región y las comunidades indígenas que ahí se encuentran y viven, se han visto duramente afectados por aquellos acontecimientos. Entre las consecuencias más graves está la imposibilidad de disfrutar de sus derechos colectivos sobre el uso de las tierras, unido a la destrucción de bienes de uso comunitario como escuelas y puestos de salud, y a la destrucción de cultivos y asesinato de animales domésticos, con graves consecuencias sobre la salud de las personas (Defensoría del Pueblo, 2003).

\section{La territorialidad Wiwa}

"Este cerro es corazón del mundo. Hay que cuidar el corazón. Cuando se para el corazón allá no valen ojos, no valen dientes, no valen manos, no valen venas. Por esto hay que protegerlo" (E5, líder Wiwa, 2015).

Arhuacos, Kankuamos, Kogis y Wiwas se consideran a sí mismos los Hermanos Mayores, y se distinguen de los Hermanos Menores - los no-indígenas de la región- por compartir la mayoría de los elementos de su cosmología y de su concepción del territorio. En particular, los cuatro Hermanos Mayores se reconocen como los guardianes de la Sierra y los encargados por los padres ancestrales de 
Alexandra D'Angelo, Restituir las tierras en el marco del posconflicto colombiano: una mirada al caso indígena Wiwa de la Sierra Nevada de Santa Marta, perifèria 22(2), diciembre 2017

\section{revistes.uab.cat/periferia}

protegerla de las amenazas y las calamidades externas. A cada uno de los cuatro pueblos indígenas ha sido entregada una zona de la Sierra por parte de Serankúa, divinidad central en la cosmología indígena de las cuatro sociedades y creador de la Ley de Origen que reglamenta los elementos del territorio. La disposición de las cuatro comunidades dentro del territorio, sin embargo, no es casual: cada pueblo es el encargado de proteger esta parte de territorio y este papel está escrito en sus nombres. Los Wiwas, por ejemplo, son los encargados de proteger las partes bajas de la Sierra, puesto que la palabra Wiwa está formada por el sufijo wi que en dumuna, el idioma Wiwa, significa "caliente": los Wiwas son la gente de tierras calientes, de los territorios bajos de la Sierra Nevada.

"Serankúa dijo Wiwa vivir en las partes bajas y [...] porque nosotros somos los dueños de abajo y tenemos que estar pendientes de lo que suceda en todo este lugar" (E5, líder Wiwa, 06/11/2015).

El mantenimiento del equilibrio espiritual en toda la Sierra Nevada de Santa Marta es un elemento muy importante en la vida de las comunidades. Aunque a cada pueblo le corresponde un área específica de la Sierra Nevada, ésta es entendida como un conjunto, una entidad que se trabaja como un todo. Es por eso, también, que la movilidad de las personas y de ciertos productos dentro de la Sierra es un elemento de suma importancia.

"Hay elementos que se traen de la parte de abajo hacia arriba para hacer pagamentos y los elementos de la parte de arriba se traen en la parte de abajo, para mantener el equilibrio. El territorio es este equilibrio. Material y espiritual" (E5, líder Wiwa, 06/11/ 2015).

De este aspecto es posible deducir hasta qué punto la inseguridad y la violencia que ha caracterizado la región ha afectado al mantenimiento espiritual de las comunidades. Cuando los miembros de la comunidad Wiwa hablaban de las afectaciones a lo largo de los años del conflicto armado, el impedimento de recorrer la Sierra de forma segura para llevar los productos de un lado a otro del territorio ha sido presentado con mucho énfasis. Además de las afectaciones al equilibrio 
Alexandra D'Angelo, Restituir las tierras en el marco del posconflicto colombiano: una mirada al caso indígena Wiwa de la Sierra Nevada de Santa Marta, perifèria 22(2), diciembre 2017

\section{revistes.uab.cat/periferia}

espiritual de las comunidades indígenas, a lo largo de las pasadas décadas no han faltado violaciones físicas. El miedo generalizado era ocasionado, también, por los continuos enfrentamientos entre los diferentes grupos armados en los lugares cercanos a los asentamientos. Algunas de las intervenciones estatales para hacer frente a la presencia del narcotráfico en la zona de la Sierra Nevada de Santa Marta han estado caracterizadas por fumigaciones incontroladas, que afectaban tanto a territorios en donde efectivamente había cultivos ilícitos, como a aquellas áreas libres de ellos. Estas quemas incontroladas han tenido consecuencias indirectas sobre los miembros de la comunidad y su territorio: enfermedades, abortos espontáneos, animales agotados y siembras malas son algunas de las afectaciones mencionadas por un miembro de la comunidad Wiwa (E6, Wiwa, 04/12/2015).

El territorio objeto de la solicitud de Restitución de Tierras por parte de la comunidad Wiwa forma parte de un vasto territorio sagrado llamado Duklindùe, que comprende un área incluida dentro de la zona de la Sierra Nevada de Santa Marta, perteneciente al Departamento del Magdalena. El territorio del Duklindùe comprende el Karrikoqui, un área en los alrededores del pueblo de Bonda, donde hay presencia de numerosos lugares sagrados para el pueblo Wiwa. Haciendo un recorrido del territorio, se aprecian restos de antiguos asentamientos y rutas ancestrales: entre los lugares más importantes, se encuentra la Piedra del Donama. Esta piedra es, para ellos, un mapa espaciotemporal que cuenta la historia de todo lo que ha pasado en el Corazón del Mundo desde sus orígenes. Los dibujos que hay grabados en la piedra representan los caminos que atraviesan la Sierra y que conectan a los Hermanos Mayores. El Donama ha estado presente en la conversación con muchas de las autoridades Wiwa, las cuales subrayaban la importancia que este lugar tiene y representa para la comunidad $y$, en consecuencia, la importancia que tendría su restitución. El territorio en cuestión cuenta con 85 hectáreas y ha visto el desplazamiento de alrededor de 20 familias Wiwa. Cabe mencionar que además de la pérdida de un territorio de gran interés espiritual, las mujeres de la comunidad han urgido a la restitución de las tierras 
Alexandra D'Angelo, Restituir las tierras en el marco del posconflicto colombiano: una mirada al caso indígena Wiwa de la Sierra Nevada de Santa Marta, perifèria 22(2), diciembre 2017 revistes.uab.cat/periferia

debido a su papel fundamental para el cultivo de productos básicos para el sustento de la comunidad.

\section{La restitución de tierras en la Sierra Nevada de Santa Marta}

La mayoría de las problemáticas relativas a las dificultades de la restitución de tierras en Colombia se repiten en la región de la Sierra Nevada de Santa Marta. Los límites temporales y el peligro que algunas zonas aún representan han sido señalados por mis interlocutores como algunos de los obstáculos para la restitución en la Sierra Nevada de Santa Marta. En particular, los miembros de la Dirección Territorial de Santa Marta han enfatizado dos problemas: primero, la extensión de los territorios que reclaman las comunidades indígenas, que requieren largos períodos de trabajo para evaluar las afectaciones territoriales, y el ya mencionado grupo A.M.E.I, que parece el obstáculo principal. Siendo el territorio de la Sierra vasto y riquísimo en recursos naturales, ha sido también objeto de mucho interés por parte de los grupos armados y del mismo Estado. Esto implicaba que cuando los territorios se iban abandonando desde las tierras bajas, "fueran utilizados por otros fines: hay siembras de banano, de palma, de cazado en sitios sagrados para las comunidades indígenas...Y en los años recientes se multiplicaron las minerías" (E7, antropólogo, 17/05/2017). Aunque en la circular interna de la Dirección de la URT, el grupo A.M.E.I es presentado como equipo de apoyo y asistencia en temas que necesitan una mirada técnica y específica sobre asuntos ambientales, en las conversaciones con mis interlocutores se ha podido apreciar cómo, en realidad, deviene un agente de control e, incluso, un obstáculo en sí mismo. En la región de la Sierra Nevada de Santa Marta nos encontramos frente a una situación compleja y paradójica: mientras que el conflicto armado y el desplazamiento han sido masivos, hoy aún no se han llevado a cabo restituciones territoriales en ninguno de los pueblos indígenas que han perdido sus territorios.

El territorio indígena comprende la capacidad de reproducir la cultura, la lengua, los derechos de autogobierno y de la propiedad colectiva de los recursos. Solamente desde este punto de vista se puede entender la concepción del "territorio como 
Alexandra D'Angelo, Restituir las tierras en el marco del posconflicto colombiano: una mirada al caso indígena Wiwa de la Sierra Nevada de Santa Marta, perifèria 22(2), diciembre 2017 revistes.uab.cat/periferia

víctima" presente en el Decreto 6533/11. Las autoridades indígenas del país, que a la hora de estipular la Ley han sido consultadas, han presionado para que el territorio fuese tratado como un ser vivo que ha sufrido las afectaciones del conflicto armado. Aunque una comunidad indígena no haya sido víctima directa de la violencia, su territorio sí lo ha sido. A pesar de su difícil aplicación, los interlocutores de la URT concuerdan en que el reconocimiento del territorio como sujeto vivo representa un desarrollo muy importante en la estipulación de restitución de los derechos territoriales étnicos, al tener en cuenta las directivas internacionales sobre los Derechos de los Pueblos Indígenas.

\section{Para concluir}

Con este artículo se ha buscado dar a conocer la Ley de Restitución de Tierras, enfatizando las características diferenciales para las comunidades indígenas de Colombia. Se han destacado las entidades involucradas en el proceso, las diferentes fases que componen las etapas de restitución y el funcionamiento de cada una de ellas. Se ha podido ver como las restituciones logradas hasta el día de hoy, y el número de demandas recibidas, no reflejan las ilusiones que el Estado, la sociedad civil, la URT y las propias comunidades indígenas tenían en el momento de la implementación de la misma. Por este motivo, se han señalado los elementos que afectan el avance del proceso, que obstaculizan y agravan su lentitud. Así, se han podido apreciar los distintos orígenes y naturaleza de los factores implicados: algunos de ellos quedan en las directivas mismas de la ley y de los límites - sobre todo temporales- que ésta exige; otros factores tienen raíces profundas en la historia del país, y tienen que ver con dificultades y vacíos que, poco a poco, el país está enfrentando, como la titulación de las tierras y la del catastro.

Los profesionales de la antropología tienen un papel muy importante dentro del proceso de restitución territorial en Colombia. Esto se manifiesta de dos maneras diferentes: por un lado, están bien radicados en la URT, y sobre todo en la Dirección de Asuntos Étnicos; de hecho, su participación en los análisis de las 
Alexandra D'Angelo, Restituir las tierras en el marco del posconflicto colombiano: una mirada al caso indígena Wiwa de la Sierra Nevada de Santa Marta, perifèria 22(2), diciembre 2017 revistes.uab.cat/periferia afectaciones es requerida directamente por la ley. Este tipo de colaboración de antropólogas y antropólogos de la URT puede ser considerado como un caso ejemplar dentro de la antropología aplicada a las políticas públicas. Por otro lado, cuando se trata de antropólogos y antropólogas contratados por las ONG, nos encontramos ante un caso de antropología aplicada a la cooperación internacional. Aquí también se trataría de una antropología de tipo orientada, en cuanto la colaboración se acaba después de la entrega de los datos a la URT. Los profesionales de la antropología en la URT también siguen el proceso hasta la etapa judicial, momento en el cual toman las riendas los jueces de la restitución. Sin embargo, en esta tercera etapa de la restitución, que es la última y la resolutiva, los profesionales de la antropología están ausentes.

No obstante la difícil implementación y las contradicciones del proceso examinado, no se pueden descuidar los procesos en que la restitución ha funcionado, o sea, los casos que han visto 27.737 beneficiarios de restitución (URT, 2017). Se considera, por tanto, que la presencia de análisis y estudios sobre situaciones de posconflicto y de reparación de las víctimas pueden ayudar a crear un conjunto de experiencias, tanto positivas como negativas, que en un futuro pueden ser ejemplos a seguir, o, al contrario, no repetir.

\section{Bibliografía}

Amnistía Internacional (2012). Colombia: la Ley de Víctimas y Restitución de Tierras. Análisis de Amnístia Internacional. Editorial Amnistía Internacional (EAI). Madrid. - 100.27105

Amnistía Internacional (2014). 15 datos sobre el proceso de restitución de tierras en Colombia. Consultable en: https://www.amnesty.org/es/latest/news/2014/11/facts-about-colombia-sland-restitution-process/. - 65.33884

Centro Nacional de Memoria Histórica (CNMH) (2013). Una guerra prolongada y 
Alexandra D'Angelo, Restituir las tierras en el marco del posconflicto colombiano: una mirada al caso indígena Wiwa de la Sierra Nevada de Santa Marta, perifèria 22(2), diciembre 2017 revistes.uab.cat/periferia

degradada. Dimensiones y modalidades de violencia. Recuperado de: http://www.centrodememoriahistorica.gov.co/descargas/informes2013/bastaY a/basta-ya-memorias-guerra-dignidad-12-sept.pdf. - 49.623653

Defensoría del Pueblo (2003). Informe de la Comisión de Observación de la Crisis Humanitaria en la Sierra Nevada de Santa Marta. Consultable en: http://www.acnur.org/t3/uploads/media/COI_244.pdf. - 82.08324

Delgado Barón, M. (2014). Memoria, conflicto armado y justicia transicional: las voces de las víctimas en la reconstrucción del pasado. Revista Historia y Justicia, 2014(3), 59-88. - 96.59038

Delgado Barón, M. (2012). Una justicia transicional sin transición: verdad, justicia, reparación y reconciliación en medio del conflicto. Revista Análisis Internacional, 4(2), 53-67. - 73.604256

Duque-Páramo, M. C. (2010). Antropología aplicada en Colombia. Perspectivas e intencionalidades a partir de una experiencia en niñez y migraciones. Pontificia Universidad Javeriana. 172-185. - 61.864433

Descola, P. (2004). Las cosmologías indígenas de la Amazonia. In: Surralles, A. y García Hierro, P. (eds) Tierra adentro. Territorio indígena y percepción del entorno. Copenhague: IWGIA, doc. N³9, 25-35. - 67.826065

Díaz, A. (1998). Unas investigaciones aplicadas. In: Hoja, pasta, polvo y roca. Naturaleza de los derivados de la coca (pp.25-34). Bellaterra: UAB. - 41.31782

Escobar, A. (1999). Cultura, ambiente y política en la antropología contemporánea. Instituto colombiano de antropología, Ministerio de Cultura, Colombia. 80.14327

García Hierro, P. \& Surrallés, A. (2004). Tierra Adentro. Territorio indígena y percepción del entorno. Barcelona, Alternativa, Intercanvi con pueblos indígenas/IWGIA: Copenhague. - 48.16422

Ley No 1448/11. Diario Oficial de la República de Colombia, Bogotá, Colombia, 10 de junio 2011.

Ley No 4333/11. Diario Oficial de la República de Colombia, Bogotá, Colombia, 6 de 
Alexandra D'Angelo, Restituir las tierras en el marco del posconflicto colombiano: una mirada al caso indígena Wiwa de la Sierra Nevada de Santa Marta, perifèria 22(2), diciembre 2017

revistes.uab.cat/periferia

diciembre 2011.

Ley No 4334/11. Diario Oficial de la República de Colombia, Bogotá, Colombia, 6 de diciembre 2011.

Ley No 4335/11. Diario Oficial de la República de Colombia, Bogotá, Colombia, 6 de diciembre 2011.

Observatorio del Programa Presidencial de Derechos Humanos (OPPDH), (2012). Diagnóstico de la situación del pueblo indígena Kogui. Consultable en: http://historico.derechoshumanos.gov.co/Observatorio/Documents/2010/Diag nosticoIndigenas/Diagnostico_KOGUI.pdf. - 62.975594

San Román, T. (2006). Acaso es evitable? El impacto de la Antropología en las relaciones e imágenes sociales. Revista de Antropología Social, 15, 373-410. 70.35124

Valcárcel, M. (2006). Génesis y evolución del concepto y enfoques sobre el desarrollo. PUCP-CISEPA: Lima. - 41.908638

Verdadabierta (2014, noviembre 26). Las críticas de Amnistía Internacional a la restitución de tierras. Consultable http://www.verdadabierta.com/restitucion-de-bienes/5528-las-criticas-deamnistia-internacional-a-la-restitucion-de-tierras. - 47.885246

Verdadabierta (2015, agosto 24). Las contradicciones de Santos con la restitución. Consultable en: http://www.verdadabierta.com/lucha-por-la-tierra/5936-lascontradicciones-de-santos-con-la-restitucion. - 41.33899

Verdadabierta (2017, enero 31). Violencia contra reclamantes de tierras, rueda suelta en Urabá. Consultable en: http://www.verdadabierta.com/victimasseccion/los-resistentes/6534-violencia-contra-reclamantes-de-tierras-ruedasuelta-en-uraba. - 90.66893

Viloria de la Hoz, J. (2005). Sierra Nevada de Santa Marta: economía de sus recursos naturales. Documentos de Trabajo Sobre Economía Regional (61), 100. - 69.86039 